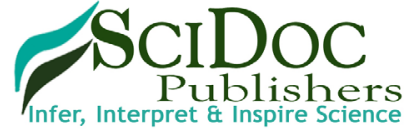

International Journal of Anesthesiology \& Research (IJAR)

ISSN 2332-2780

\title{
Comparison of $0.5 \%$ Ropivacaine and $0.2 \%$ Ropivacaine in Bilateral Transversus Abdominis Plane Block in Laparoscopic Abdominal Surgeries
}

Research Article

Pratima B Patil ${ }^{1}$, Aiman Anjum ${ }^{2 *}$

${ }^{1}$ Associate Professor, Department of Anaesthesiology, Mahadevappa Rampure, Medical College, Kalaburgi, Karnataka, India.

${ }^{2}$ Post graduate MD Anaesthesia, Department of Anaesthesiology, Mahadevappa Rampure, Medical College, Kalaburgi, Karnataka, India.

\section{Abstract}

Background and Aims: Transversus abdominis plane (TAP) block is a popular regional anaesthesia technique for postoperative analgesia after abdominal surgeries. The aim of the study was to evaluate the relative efficacy of 2 concentrations of ropivacaine for post-operative analgesia using ultrasound-guided TAP block in laparoscopic abdominal surgeries.

Methods: Sixty adults undergoing elective laparoscopic abdominal surgeries were randomised to receive ultrasound-guided TAP block at the end of the surgical procedure before extubation with either $0.5 \%$ ropivacaine (Group $\mathrm{A}, \mathrm{n}=30$ ) or $0.2 \%$ ropivacaine (Group B, n = 30). All patients were assessed for post-operative pain and rescue analgesic consumption at $0,2 \mathrm{~h}$, $4 \mathrm{~h}, 8 \mathrm{~h}, 12 \mathrm{~h}$ and $24 \mathrm{~h}$ time points. Means for normally distributed data were compared using unpaired t-test, and proportions were compared using Chi-square or Fisher's exact test whichever was applicable.

Results: Patients receiving ultrasound-guided TAP block with 0.5\% ropivacaine (Group A) had significantly lower pain scores when compared to patients who received the block with $0.2 \%$ ropivacaine (Group B) at $2 h, 4 h, 8 h, 12 h$ and 24 h. The mean time required for the first rescue analgesia (after administration of block) in hours was significantly higher in Group A as compare to Group B The mean 24 hours Opioid requirement (No. of doses of inj. Tramadol $50 \mathrm{mg}$ IV) was significantly lower in group A as compare to Group B.

Conclusion: Ultrasound-guided TAP block with $0.5 \%$ ropivacaine provides effective and longer analgesia in the post-operative period as compared to $0.2 \%$ ropivacaine. And lesser 24 hour opiod requirement.

Keywords: Laparoscopic Surgeries; Ropivacaine; Transversus Abdominis Plane Block.

\section{Introduction}

The abdominal wall is significant source of pain after abdominal surgery. Laparoscopic surgery is a popular method of surgery with many advantages. Despite the minimally invasive nature,pain can be moderate to severe in Immediate post operative period [1].

The pain experienced by patients after abdominal surgery is derived from the anterior abdominal wall incision. The anterior abdominal wall is innervated by nerve afferents that course through the transversus abdominis neurovascular fascial plane [2].

The usual trend is to prescribe an opioid or non steroid anti inflammatory drugs (NSAIDS) for post operative analgesia. Regional anaesthesia technique has gained widespread popularity as an important component of post operative analgesia regimen.
The transversus abdominals plane block is a regional anesthesia technique that provides analgesia to the parietal peritoneum as well as skin and muscles of the anterior abdominal wall . It has been shown to be a safe and effective post operative adjunct analgesia method in a variety of surgical procedures and it is suggested as part of the multimodal anaesthetic approach to enhance recovery after abdominal surgeries [3]. It allows sensory blockade of plexus of nerves supplying abdominal wall, skin and muscles via local anaesthetic drug deposition.

The present study is to compare the duration of post operative analgesia and 24 hour opioid requirement conferred by $0.5 \%$ ropivacaine and $0.2 \%$ ropivacaine used in transvesus abdominis plane block for laparoscopic abdominal surgeries $[4,5]$.

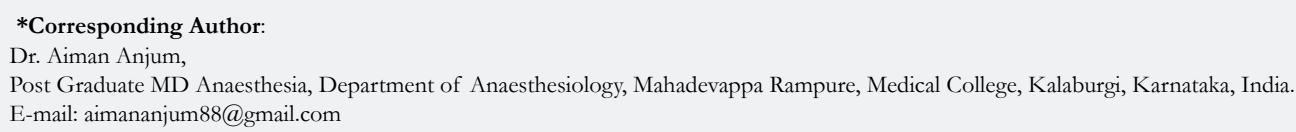

Citation: Pratima B Patil, Aiman Anjum. Comparison of 0.5\% Ropivacaine and 0.2\% Ropivacaine in Bilateral Transversus Abdominis Plane Block in Laparoscopic Abdominal Surgeries. Int J Anesth Res. 2020;8(5):606-610. doi: http://dx.doi.org/10.19070/2332-2780-20000121

Copyright: Aiman Anjum ${ }^{\circ}$ 2020. This is an open-access article distributed under the terms of the Creative Commons Attribution License, which permits unrestricted use, distribution and reproduction in any medium, provided the original author and source are credited. 


\section{Methods}

After the Institutional Ethics Committee approval, sixty American Society of Anaesthesiologists Physical Status I/II patients of either sex, aged 18-60 years, scheduled to undergo elective laparoscopic surgery were enrolled in this study. Patients with a history of allergy to test drugs, drug abuse, coagulation disorders or patients on anticoagulants and patients with abdominal infections were excluded from the study. The patients were randomly allocated into two groups to receive TAP block with either $0.5 \%$ ropivacaine and $0.2 \%$ ropivacaine solution.

Patients were randomly allocated into two groups, one group to undergo ultrasound-guided TAP block with $0.5 \%$ ropivacaine (Group A, $\mathrm{n}=30$ ) and other group to undergo ultrasound-guided TAP block with $0.2 \%$ ropivacaine (Group $\mathrm{B}, \mathrm{n}=30$ ).

After pre anaesthetic evaluation valid, written, informed consent was obtained from all patients both for conduct of study as well as for administration of general anaesthesia.

All patients were kept nil by mouth from midnight before surgery and tablet Alprazolam $(0.01 \mathrm{mg} / \mathrm{kg})$ was administered at bed time, the day before surgery.

In the operating room, routine monitors were applied and venous access was secured. Patients were premedicated with inj ondansetron $0.1 \mathrm{mg} / \mathrm{kg}$, inj glycopyrrolate $0.005 \mathrm{mg} / \mathrm{kg}$, inj midazolam $0.05 \mathrm{mg} / \mathrm{kg}$, following pre-oxygenation, the patients received IV fentanyl $(2 \mu \mathrm{g} / \mathrm{kg})$. Anaesthesia was induced with IV propofol 2 $\mathrm{mg} / \mathrm{kg}$. Vecuronium bromide $(0.1 \mathrm{mg} / \mathrm{kg}) \mathrm{IV}$ was utilised to facilitate tracheal intubation. Anaesthesia was maintained with nitrous oxide $(60 \%)$ and isoflurane $(0.5-1 \%)$ in oxygen.

At the end of surgery with Patient in supine position under all aseptic precautions ultrasound is kept midway between the coastal margin and iliac crest in the midaxillary line. The muscles are identified. The needle is gradually passed through skin, subcutaneous tissue, external oblique and internal oblique until the needle tip is placed between internal oblique and transversus abdominis muscle, after aspiration $2-3 \mathrm{ml}$ of local anaesthetic drug is given and spread of drug is seen. After confirmation $20 \mathrm{ml}$ of local anaesthetic is given on both sides.

Anaesthesiologist who observed the patient in post operative period is blinded to the drug injected in TAP block. Patients are monitored at 2, $4,6,12,24$ hrs post operatively for heart rate, blood pressure, saturation, pain, no of episodes of nausea and vomiting and complications if any. Duration of analgesia will be from the time of administration of transversus abdominis plane block to administration of first rescue analgesia. All patients will be educated regarding the use of VAS scoring [6] from scale 1 to 10 in which 0 means no pain 10 means worst pain as depicted in figure no 1. Rescue analgesia ( inj tramadol 50mg diluted IV slowly) will be given when VAS score is 4 or more.

The number of episodes of retching, nausea and vomiting in 24 hrs post operative period, severity is graded as:

\section{Mild: 1}

Moderate: 2

Severe: 3

\section{Statistical analysis}

Statistical data was analysed by SPSS 20.0 version software. Collected data were spread on excel sheet and prepared master chart. Through the master chart tables, graphs and diagrams were prepared. For qualitative data analysis chi-square test was applied; for quantitative data analysis unpaired $t$ test was applied for statistical significance. If P-value was less than 0.05 considered as significant.

Sample size calculation for 2 different groups of equal sizes for a continuous outcome measure.

$\mathrm{n}=$ sample size per group

$\alpha=0.05$ The probability of rejecting the null hypothesis when it is true. A level of 0.05 or $95 \%$ is most commonly used. the value was 1.96 .

$\beta=0.2$ The probability of failing to reject the null hypothesis if it is false. A level of 0.2 is most commonly used. This corresponds to a study power of 0.8 or $80 \%$.

$\sigma 2=$ population variance in mean time to union (standard deviation $^{2}$ ) the $\mathrm{SD}$ of the study was 18 in the reference study (The sample size was estimated based on the 24-hour morphine requirement in a previous study by Niraj et al. [7]) in Acta Anaesthesiologica Taiwanica.

$\mu_{1}=$ Mean of group $\mathrm{A}$

$\mu_{2}=$ Mean of group B

$\mu_{2}-\mu_{1}=$ minimum difference was 12.9

Sample size $=\left(\mathrm{Z}_{\alpha / 2}+\mathrm{Z}_{\beta}\right)^{2} \times 2 \sigma^{2} / \mu_{2}-\mu_{1}$

$=(1.96+0.82)^{2} \times 2 \times(18)^{2} /(12.9)^{2}$

$=30$ samples in each group

Figure 1.

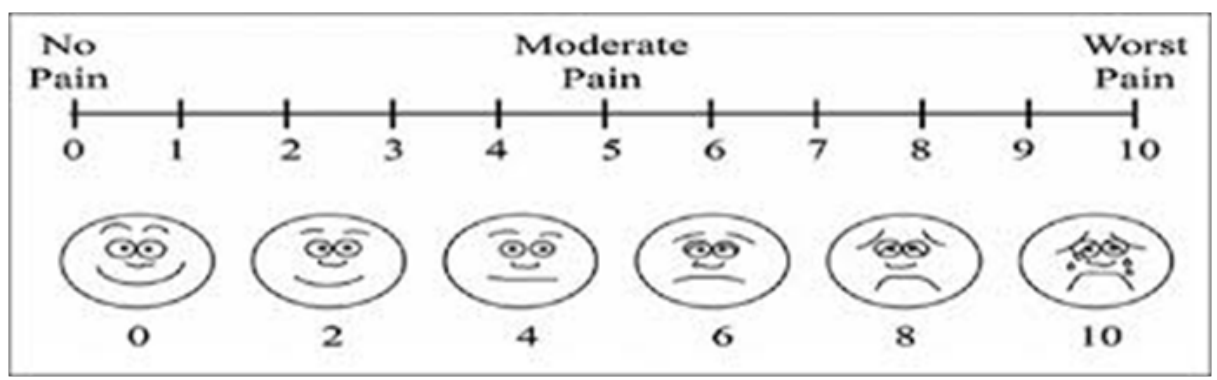

Pratima B Patil, Aiman Anjum. Comparison of 0.5\% Ropivacaine and 0.2\% Ropivacaine in Bilateral Transversus Abdominis Plane Block in Laparoscopic Abdominal Surgeries. Int J Anesth Res. 
Sample size $=$ Total samples 60 (30 samples were taken in each group).

There was no difference in the demographic data (age, gender, body weight and height). There was no statistical significant difference of mean VAS pain score between Group A and Group B at 0 hours $(\mathrm{P}>0.05)$.

There was statistically highly significant difference of mean VAS pain score between Group A and Group B at 2 hours $(\mathrm{P}<0.002)$.

There was statistically very highly significant difference of mean VAS pain score between Group A and Group B at 4 hours, 8 hours, 12 hours and 24 hours of $(\mathrm{P}<0.001)$.

The mean VAS pain score were significantly higher in Group B as compare to Group A At 2 hours, 4 hours, 8 hours, 12 hours and 24 hours.

There was statistically very high significant difference of mean Time required for the first rescue analgesia (after administration of block) in hours between Group A and Group B ( $<<0.001)$.

The mean time required for the first rescue analgesia (after administration of block) in hours was significantly higher in Group A (Inj. 0.5\% Ropivacaine) as compare to Group B (Inj.0.2\% Ropivacaine).
There was statistically very high significant difference of mean 24 hours opioid requirement (No. of doses of inj. Tramadol $50 \mathrm{mg}$ IV) between Group A and Group B ( $<<0.001)$.

The mean 24 hours OPIOD requirement (No. of doses of inj. Tramadol $50 \mathrm{mg}$ IV) was significantly lower in group A as compare to Group B.

Comparison of Time required for the first rescue analgesia, Incidence of post operative nausea and vomiting and 24 hours OPIOD requirement cases between Group A and Group B.

\section{Results}

Group A that is Inj.0.5\% Ropivacaine was significantly better as compare to Group B Inj. 0.2\% Ropivacainein relieving pain.The mean time required for the first rescue analgesia (after administration of block) in hours was significantly higher in Group A ( mean time 24.23 hours)as compared to Group B (mean time 5.57 hours). The mean 24 hours opioid requirement (No. of doses of inj. Tramadol $50 \mathrm{mg}$ IV) was significantly lower in group $\mathrm{A}$ as compare to Group B.

\section{Discussion}

The benefits of adequate postoperative analgesia are clear and include a reduction in the postoperative stress response, reduction in postoperative morbidity, in certain types of surgery, there is

Table 1. Group A and Group B.

\begin{tabular}{|c|c|c|c|c|c|}
\hline \multirow{3}{*}{ Time Period } & \multicolumn{5}{|c|}{ VAS score } \\
\hline & Group A & Group B & \multirow{2}{*}{$\begin{array}{c}\text { Std. Er- } \\
\text { ror }\end{array}$} & \multirow{2}{*}{$\mathrm{t}$-test value } & \multirow{2}{*}{ P- value \& Significance } \\
\hline & Mean \pm SD & Mean \pm SD & & & \\
\hline 0 hours & $0.00 \pm 0.00$ & $0.17 \pm 0.53$ & 0.096 & $t=1.723$ & $\mathrm{P}=0.091, \mathrm{NS}$ \\
\hline 2 hours & $0.00 \pm 0.00$ & $0.89 \pm 1.39$ & 0.245 & $t=3.515$ & $\mathrm{P}=0.002, \mathrm{HS}$ \\
\hline 4 hours & $0.33 \pm 0.60$ & $2.67 \pm 1.24$ & 0.253 & $\mathrm{t}=9.252$ & $\mathrm{P}=0.000, \mathrm{VHS}$ \\
\hline 8 hours & $1.43 \pm 0.50$ & $4.43 \pm 0.56$ & 0.132 & $t=21.632$ & $\mathrm{P}=0.000, \mathrm{VHS}$ \\
\hline 12 hours & $1.73 \pm 0.69$ & $4.96 \pm 0.31$ & 0.135 & $\mathrm{t}=23.241$ & $\mathrm{P}=0.000, \mathrm{VHS}$ \\
\hline 24 hours & $2.86 \pm 1.27$ & $5.03 \pm 0.80$ & 0.274 & $\mathrm{t}=7.843$ & $\mathrm{P}=0.000, \mathrm{VHS}$ \\
\hline
\end{tabular}

NS = not significant, $\mathrm{S}=$ significant, HS = highly significant, VHS = very highly significant

Figure 2. Line Diagram Represents mean VAS pain Score of the Cases.

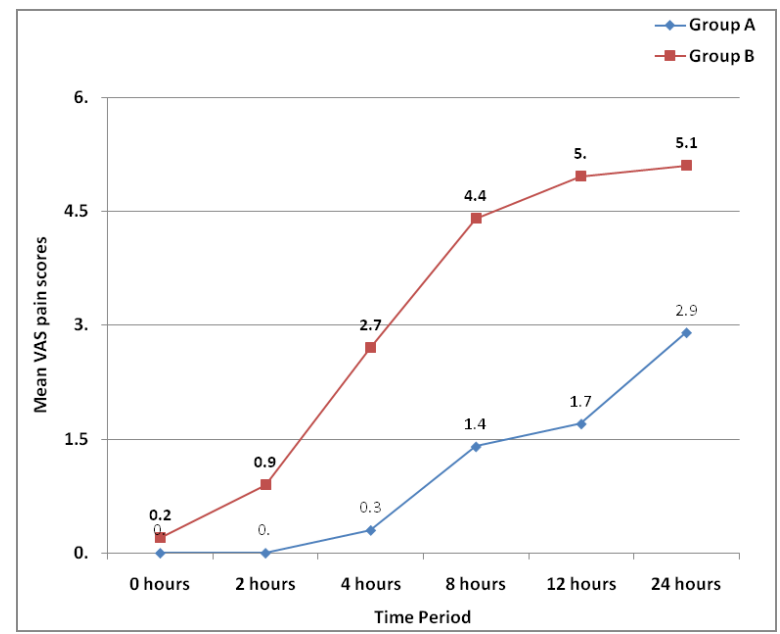


improved surgical outcome. Effective pain control also facilitates rehabilitation and accelerates recovery from surgery. Other benefits of effective regional analgesic techniques include reduced pain intensity, decreased incidence of side effects from analgesics and improved patient comfort [8], and early discharge from the hospital.

Using local anaesthetic agents in transversus abdominis plane block (TAPB) is a simple and effective analgesic technique, appropriate for surgical procedures where parietal pain is a significant component of postoperative pain. The local anaesthetic agents in TAP block have been demonstrated to provide excellent analgesia to the skin and musculature of the anterior abdominal wall in patients undergoing colonic resection surgery involving a midline abdominal wall incision.

The TAP block is an ideal and novel intervention in postoperative pain management for lower abdominal surgeries. As compared to the traditional epidural analgesia and parenteral analgesics, the TAP block offers innumerable advantages such as decreased hemodynamic perturbations, decreased respiratory depression, nausea, vomiting, decreased cost, and overall patient satisfaction [9].

In this study local anaesthetic agents like $0.5 \%$ ropivacaine and $0.2 \%$ ropivacaine used in TAPB produced effective and prolonged postoperative analgesia.

Patients in group A had pain relief of upto 24 hours while patients in group B had pain relief only upto 5 hours postoperatively. 24 hour opioid requirement was less in group A compared to group B.

Though there was no significant difference between the 2 groups

Table 2.

\begin{tabular}{|c|c|c|c|c|c|}
\hline Variables & Group A & Group B & Std. Error & t - test value & $\begin{array}{c}\text { P- value \& Sig- } \\
\text { nificance }\end{array}$ \\
\cline { 2 - 5 } & Mean \pm SD & Mean \pm SD & & & $\mathrm{P}=0.000, \mathrm{VHS}$ \\
\hline $\begin{array}{c}\text { TIME OF FIRST RESCUE ANAL- } \\
\text { GESIA (AFTER ADMINISTRA- } \\
\text { TION OF BLOCK) in hours }\end{array}$ & $24.23 \pm 1.38$ & $5.57 \pm 1.30$ & 0.342 & $\mathrm{t}=53.80$ & $\mathrm{P}=0.000, \mathrm{VHS}$ \\
\hline $\begin{array}{c}24 \text { HOUR OPIOD REQUIREMENT } \\
\text { (no. of doses of injection tramadol 50 } \\
\text { mg IV) }\end{array}$ & $0.40 \pm 0.49$ & $3.23 \pm 1.24$ & 0.152 & $\mathrm{t}=18.43$ & $\mathrm{P}$ \\
\hline
\end{tabular}

NS = not significant, $\mathrm{S}=$ significant, HS = highly significant, VHS = very highly significant.

Figure 3. Simple bar diagram represents comparison of mean Time required for the first rescue analgesia among Group A and Group B.

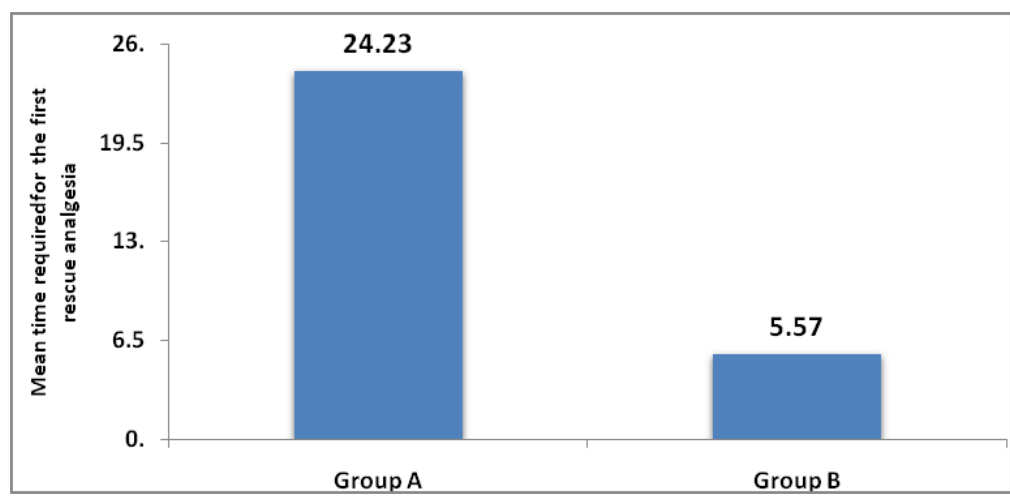

Figure 4. Simple bar diagram represents comparison of mean 24 hours OPIOD requirement among Group A and Group B.

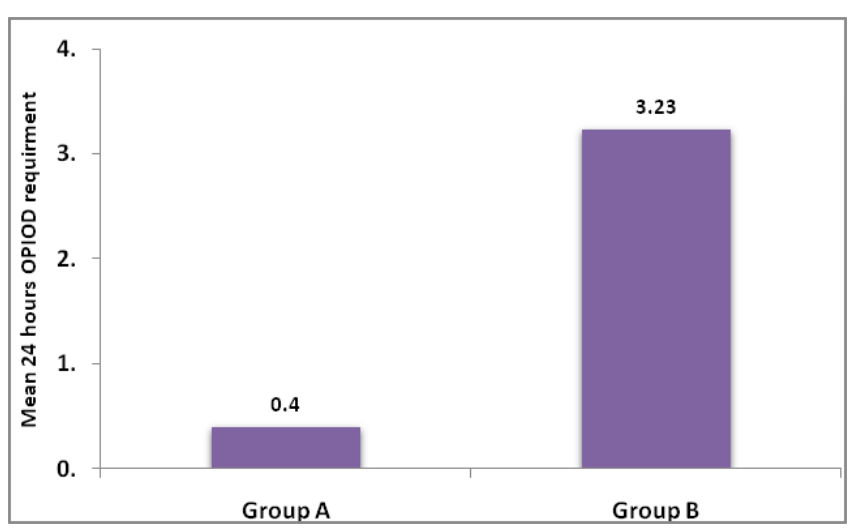


in terms of post operative nausea vomiting but it was less in group A as compared to group B. Patients in group A were more comfortable in post operative period.

Patient receiving $0.5 \%$ ropivacaine had longer post operative analgesia as compared to $0.2 \%$ ropivacaine even when laparoscopic surgeries were converted to open surgeries.

Some of the similar studies have been conducted in past few years Chen and Phui [10] found that injection of $20 \mathrm{ml}$ of ropivacaine $0.375 \%$ for TAP block was effective as intraoperative and postoperative analgesic in 10 cases of laparoscopic cholecystectomy even after they were diverted to open cholecystectomy. Abdul Jalil et al. [11] in their prospective, randomized, double blind study on 56 patients scheduled for appendectomy under general anesthesia and theyreceived TAP block with ropivacaine $0.2 \%$ in one group and ropivacaine $0.5 \%$ in the other group at the end of the surgery and they found that both concentrations provided comparable postoperative analgesia.

Oliviera et al. [12] in their prospective randomized, double blinded, placebo controlled study on 98 females scheduled for outpatient gynecological laparoscopyin which they compared between ropivacaine $0.25 \%$ and ropivacaine $0.5 \%$ in TAP block to provide postoperative analgesia and they found that there was no signficant difference between the two concentrations in their analgesic potency and no signficant difference in parturients satisfaction score between the two concentrations. The present study has certain limitations. The pain scores at movement have not been taken into account despite the fact that laparoscopic surgeries are aimed to facilitate early ambulation. The serum concentrations of the drugs administered in the TAP were not estimated.

\section{Conclusion}

We conclude with our study that $0.5 \%$ Ropivacaine as compared to $0.2 \%$ ropivacaine used in Transversus abdominis plane block for laparoscopic surgeries of abdomen provided longer duration of post operative analgesia and 24 hour opioid requirement was also less in $0.5 \%$ ropivacaine group.

\section{References}

[1]. Zhao X, Tong Y, Ren H, Ding XB, Wang X, Zong JY, et al. Transversus abdominis plane block for postoperative analgesia after laparoscopic surgery: a systematic review and meta-analysis..Int j Exp Med . 2014;7(9):2966-2975.

[2]. Netter FH. Back and spinal cord. Atlas of human anatomy summit. New Jersey, USA: The Ciba-Geigy Corporation. 1989:145-55.

[3]. Young MJ, Gorlin AW, Modest VE, Quraishi SA. Clinical implications of the transversus abdominis plane block in adults. Anesthesiology Research and Practice. 2012 Jan 1;2012.

[4]. El Abdein Mohamed AZ. Assessment of the analgesic potency of ropivacaine $0.2 \%$ versus ropivacaine $0.5 \%$ in transversus abdominis plane block after cesarean delivery. Egyptian Journal of Anaesthesia. 2016 Jul 1;32(3):385-90.

[5]. Jain S, Kalra S, Sharma B, Sahai C, Sood J. Evaluation of ultrasound-guided transversus abdominis plane block for postoperative analgesia in patients undergoing intraperitoneal onlay mesh repair. Anesthesia, essays and researches. 2019 Jan;13(1):126.

[6]. Haefeli M, Elfering A. Pain assessment. European Spine Journal. 2006 Jan 1;15(1):S17-24.

[7]. Niraj G, Searle A, Mathews M, Misra V, Baban M, Kiani S, Wong M. Analgesic efficacy of ultrasound-guided transversus abdominis plane block in patients undergoing open appendicectomy. British journal of anaesthesia. 2009 Oct 1;103(4):601-5.

[8]. Fuladi N, Deshmukh S, Bhure A. Comparative study of bupivacaine $0.25 \%$ versus ropivacaine $0.5 \%$ in transversus abdominis plane block for postoperative analgesia in lower abdominal surgeries: a randomised controlled trial. Journal of Evolution of Medical and Dental Sciences. $2014 \mathrm{Apr}$ 28;3(17):4569-77.

[9]. Baeriswyl M, Zeiter F, Piubellini D, Kirkham KR, Albrecht E. The analgesic efficacy of transverse abdominis plane block versus epidural analgesia: a systematic review with meta-analysis. Medicine. 2018 Jun;97(26).

[10]. Chen CK, Phui VE. The efficacy of ultrasound-guided oblique subcostal transversus abdominis plane block in patients undergoing open cholecystectomy. Southern African Journal of Anaesthesia and Analgesia. 2011;17(4):308-10.

[11]. Jalil RM, Yahya N, Sulaiman O, Mat WR, Teo R, Izaham A, Rahman RA. Comparing the effectiveness of ropivacaine $0.5 \%$ versus ropivacaine $0.2 \%$ for transabdominis plane block in providing postoperative analgesia after appendectomy. Acta Anaesthesiologica Taiwanica. 2014 Jun 1;52(2):49-53.

[12]. De Oliveira Jr GS, Fitzgerald PC, Marcus RJ, Ahmad S, McCarthy RJ. A dose-ranging study of the effect of transversus abdominis block on postoperative quality of recovery and analgesia after outpatient laparoscopy. Anesthesia \& Analgesia. 2011 Nov 1;113(5):1218-25. 